\title{
Taxonomy of the Myrmicine ant genus Temnothorax Mayr, 1861 (Formicidae: Myrmicinae) in the Arabian Peninsula
}

\author{
Mostafa R. SHARAF ${ }^{1}$, Shahid A. AKBAR ${ }^{2, *}$, Hathal M. AL DHAFER ${ }^{3}$, \\ Ali El-GHARBAWY ${ }^{4}$, Abdulrahman S. ALDAWOOD ${ }^{5}$ \\ 1,3,4,5 Plant Protection Department, College of Food and Agriculture Science, King Saud University, \\ Riyadh 11451, P.O. Box 2460, Saudi Arabia. \\ ${ }^{2}$ Plant Protection Division, Department of Entomology, Central Institute of Temperate Horticulture, \\ Srinagar, Jammu and Kashmir, India. \\ ${ }^{4}$ Zoology Department, Faculty of Science, Al Azhar University, Nasr City, Cairo, Egypt. \\ ${ }^{*}$ Corresponding author: kingakbarali@gmail.com \\ ${ }^{1}$ Email: antsharaf@gmail.com \\ ${ }^{3}$ Email: hdhafer@ksu.edu.sa \\ ${ }^{4}$ Email: aali@ksu.edu.sa \\ ${ }^{5}$ Email: aldawood88@yahoo.com
}

\footnotetext{
${ }^{1}$ urn:1sid:zoobank.org:author:E2A42091-0680-4A5F-A28A-2AA4D2111BF3

${ }^{2}$ urn:1sid:zoobank.org:author:5A0AC4C2-B427-43AD-840E-7BB4F2565A8B

${ }^{3}$ urn:lsid:zoobank.org:author:6117A7D3-26AF-478F-BFE7-1C4E1D3F3C68

${ }^{4}$ urn:Isid:zoobank.org:author:CF07A94C-9C29-4187-B7F9-622887D02764

${ }^{5}$ urn:1sid:zoobank.org:author:477070A0-365F-4374-A48D-1C62F6BC15D1
}

\begin{abstract}
The Arabian Temnothorax Mayr, 1861 fauna is revised for the first time. Three species are recognized from the region: Temnothorax arabicus Sharaf \& Akbar sp. nov., T. liviae (Agosti \& Collingwood, 2011) comb. nov. and T. megalops (Hamann \& Klemm, 1967). Leptothorax saudiae Collingwood \& Agosti, 1996 was placed in Temnothorax by Bolton (2003), but actually belongs to Tetramorium Mayr, 1855 and is herewithin recombined to Tetramorium saudiae (Collingwood \& Agosti, 1996) comb. nov. Automontage images and comparative diagnoses of workers as well as notes on habitats and distribution of treated species are provided. A revised key to the Arabian species based on the worker caste is also presented.
\end{abstract}

Keywords. Ants, Temnothorax, revision, Kingdom of Saudi Arabia, Afrotropical region.

Sharaf M.R., Akbar S.A., Al Dhafer H.M., El-Gharbawy A., Aldawood A.S. 2017. Taxonomy of the Myrmicine Ant Genus Temnothorax Mayr, 1861 (Formicidae: Myrmicinae) in the Arabian Peninsula. European Journal of Taxonomy 280: 1-17. http://dx.doi.org/10.5852/ejt.2017.280

\section{Introduction}

The ant genus Temnothorax Mayr, 1861 is widespread and currently represented by 431 valid species and subspecies (Bolton 2017). The majority of species are Holarctic in distribution with more than half 
of the described species from Europe and the Mediterranean basin (Prebus 2015; Csösz et al. 2015). A few species are reported from sub-Saharan Africa and a notable radiation is also prevalent in the Caribbean region (Baroni 1978). The genus Temnothorax has been in a state of confusion ever since its original description. Bolton (2003) removed the genus from synonymy under Leptothorax Mayr, 1855 and provided a new verve to study of the genus. Ward et al. (2015) subsumed Formicoxenini under Crematogastrini and emphasized unresolved relationships among members within the clade. The socially parasitic genera Chalepoxenus Menozzi, 1923 and Myrmoxenus Ruzsky, 1902 were also synonymized under Temnothorax (Ward et al. 2015). Seifert et al. (2016) expressed doubts about such phylogenetic classification by considering it as "not an actual reflection of the information content of evolution". The genus Temnothorax awaits a global taxonomic revision; however, some of the noteworthy contributions to the genus include those of Radchenko (2004, 2005, eastern Palaearctic species key), Seifert (2007, North and Central Europe), Schulz et al. (2007, Italy), Terayama (2009, Taiwan), Zhou et al. (2010, China), Plateaux \& Cagniant (2012, synonymy list of the genus), Czechowski et al. (2012, Poland), Bharti et al. (2012, India), Reyes-López \& Carpintero-Ortega (2013, Iberian peninsula), Snelling et al. (2014, California), Prebus (2015, Afrotropical regions), Salata \& Borowiec (2015, eastern Mediterranean), Seifert \& Csősz (2015, Eurocaucasian region) and Csősz et al. (2015, PontoMediterranean region). Moreover, recent papers by Galkowski \& Lebas (2016), Hita et al. (2017), Bharti et al. (2016) and Sharaf et al. (2017) are also pertinent to this study.

The majority of species of Temnothorax are known to maintain small colony sizes often including less than 200-300 individuals. Several species of the genus have been reared under controlled laboratory conditions for studies on population growth (Buschinger 1968, 1974), colony structure, pronounced kin conflict (Heinze 2004), social parasites, guest ants, slave-makers, workerless inquiline behavior (Buschinger 1981, 1986, 2009; Hölldobler \& Wilson 1990), and behavioral ecology (Aleksiev et al. 2007; Pratt et al. 2005; Dornhaus \& Franks 2006; Franks \& Richardson 2006; Basari et al. 2014). These ants have a wide habitat range and variety of feeding habits (Mackay 2000; Fokuhl et al. 2012). The use of light traps and the handpicking method during evening hours enhance opportunities for collection as these ants are mostly nocturnal and dusk foragers. Social parasitism is exhibited by several species of the genus. Diagnoses of the morphologically similar and sympatric genera Temnothorax, Nesomyrmex Wheeler, 1910, Leptothorax and Tetramorium Mayr, 1855 are presented in detail by Bolton (1982), Radchenko (2004) and Prebus (2015).

In the Arabian Peninsula, Temnothorax has received relatively little attention. Only a few isolated descriptions have been published from the region. Collingwood \& Agosti (1996) listed six taxa of Temnothorax occurring in the Arabian Peninsula and formerly assigned to the genus Leptothorax: L. humerosus (Emery, 1846), L. angulatus (Mayr, 1862) and L. saudiae (Collingwood \& Agosti, 1996), plus three undescribed species (Leptothorax A, B, C). Bolton (2003) transferred L. humerosus and L. angulatus to the genus Nesomyrmex. Collingwood et al. (2011) described a new species, L. liviae, and reported L. megalops for the first time from the UAE. The three undescribed species (Collingwood \& Agosti 1996) were never established as valid species and cannot be found in the World Museum Liverpool Collection, Liverpool, United Kingdom (WMLC), where Collingwood's collection is deposited.

\section{Material and methods}

The material examined in this study was collected by pitfall traps, Malaise traps, and hand searching methods during surveys carried out in different regions of the Kingdom of Saudi Arabia (KSA) from 2010 to 2015. Type material of the treated species conserved in different museums (WMLC, KSMA, NHMB, NHMW, and CASC) was also studied and compared. Morphological examinations were conducted using a Nikon SMZ 1500 stereo zoom microscope. Digital color images of lateral and dorsal views of the entire body and full-face views of the head of each species were created using a Leica DFC450 digital camera with a Leica Z16 APO microscope and Leica Application Suite LAS (v3.8) 
software. These images are also available online on AntWeb (www.AntWeb.org) and are accessible using the unique identifying specimen code.

\section{Abbreviations for morphological terms}

Throughout the text, 'w' stands for 'worker' or 'workers' and 'q' for 'queen'.

All measurements are given in millimeters following Seifert (2006), Snelling et al. (2014) and Prebus (2015):

EL = Eye length; the maximum length of the compound eye in profile, including nonpigmented facets

FRS $=$ The distance of the frontal carinae immediately caudal of the posterior intersection points between frontal carinae and the lamellae dorsal of the torulus

HFL = Hind femoral length; the maximum length of hind femur in dorsal view, excluding trochanter

HFW $=$ Hind femoral width; the maximum width of hind femur in dorsal view

HL = Head length; in frontal view, the maximum length of head from the mid-point of the anterior clypeal margin to posterior margin of the head

HW $=$ Head width; the maximum width of head in frontal view, excluding eyes

$\mathrm{IOD}=$ Interocular distance; the minimum distance between compound eyes in frontal view

IOcD = Inter-ocellar distance; the minimum distance between the posterior-most pair of ocelli, applies to queens

OMD = Oculomandibular distance or malar distance $(\mathrm{MD}=$ malar distance in Seifert 2006). The shortest length of malar area, measured in profile the shortest distance between the anterior margin of the eye and the base of the mandible

$\mathrm{PPTH}=$ Postpetiole height; the maximum height of the postpetiole measured in lateral view from the highest (median) point of the node to the ventral outline

PPTL = Postpetiole length; the maximum length of postpetiole measured in dorsal view, excluding helcium

PPTW $=$ Postpetiole width; the maximum width of postpetiole measured in dorsal view

PTH $=$ Petiole height: the maximum height of the petiole, measured from the apex of the node to the ventral edge of petiole, parallel to the anterior margin of the petiole

PTL $=$ Petiole length; the maximum length of the petiole is measured in dorsal view from the anterior notch close to the propodeum to the articulation with the postpetiole

PTW $=$ Petiole width; the maximum width of petiole measured in dorsal view

$\mathrm{PW}=$ Pronotal width; the maximum width of pronotum in dorsal view

SPST $=$ The distance between the center of the propodeal stigma (spiracle) and spine tip. The stigma center refers to the midpoint defined by the outer cuticular ring but not to the center of the stigma opening, which may be positioned eccentrically (Seifert 2006)

$\mathrm{SL}=$ Scape length; the maximum straight-line length of scape shaft excluding condyle

$\mathrm{WL}=$ Weber's length; the diagonal length of mesosoma in profile, from the posteroventral margin of propodeal lobe to the anterior-most point of pronotal slope, excluding the neck

\section{Indices}

CI $=$ Cephalic index $($ HW/HL $\times 100)$

FI $=$ Femoral length index $($ HFL $/ H W \times 100)$

$\mathrm{OI}=$ Ocular index $(\mathrm{EL} / \mathrm{HW} \times 100)$

$\mathrm{PI}=$ Petiole node index $(\mathrm{PTW} / \mathrm{PW} \times 100)$

PSLI $=$ Propodeal spine index $(\mathrm{SPST} / \mathrm{HL} \times 100)$

SI $=$ Scape index $(\mathrm{SL} / \mathrm{HL} \times 100)$ 


\section{Institutional abbreviations}

CASC $=$ California Academy of Sciences Collection, San Francisco, U.S.A.

KSMA $=$ King Saud University Museum of Arthropods, Plant Protection Department; College of Food and Agriculture Sciences, King Saud University, Riyadh, Kingdom of Saudi Arabia

NHMB $=$ Naturhistorisches Museum, Basel, Switzerland

NHMW $=$ Naturhistorisches Museum Wien, Vienna, Austria

WMLC $=$ World Museum Liverpool Collection, Liverpool, U.K.

\section{Results}

Family Formicidae Latreille, 1809

Subfamily Myrmicinae Lepeletier, 1835

Tribe Crematogastrini Forel, 1893

Genus Temnothorax Mayr, 1861

Temnothorax arabicus Sharaf \& Akbar sp. nov.

urn:lsid:zoobank.org:act:CB6D46D1-BBFB-436A-B806-D5423765F053

Figs 1-3

\section{Etymology}

The new species Temnothorax arabicus sp. nov. is named after the Arabian Peninsula.

\section{Type material}

\section{Holotype worker}

SAUDI ARABIA: Asir, Abha, Raydah, $18^{\circ} 12.315^{\prime}$ N, 42 $2^{\circ} 24.607^{\prime}$ E, alt. 2761 m, 26 Jul. 2014, M.R. Sharaf leg. CASENT0746640 (KSMA).

\section{Paratypes}

SAUDI ARABIA: $1 \mathrm{w}$, same data as the holotype, 5 Mar. 2015, Al Dhafer et al. leg. (PT) (KSMA); $3 \mathrm{w}$,

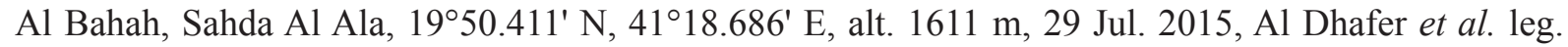
(PT) (KSMA, 1 in CASC); 1 w, Al Bahah, Shohba Forest, 20².723' N, 41 ${ }^{\circ} 28.565^{\prime}$ E, 14 May 2010,

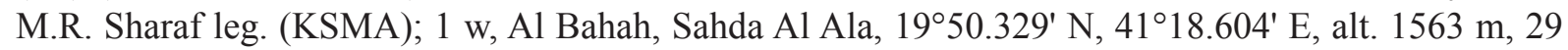
Jul. 2015, Al Dhafer et al. leg. (PT) (KSMA); 1 w, Al Bahah, Sahda Al Ala, 1950.710' N, 411․267' E, alt. 1474 m, 29 Jul. 2015, Al Dhafer et al. leg. (PT), (KSMA); 2 w, Al Bahah, Sahda Al Ala, 1950.411' N, 41 ${ }^{\circ} 18.6866^{\prime}$ E, alt. 1611 m, 2 Mar. 2015, Al Dhafer et al. leg. (PT) (KSMA); 1 w, Wadi Shahdan, Jizan, $17^{\circ} 45.222^{\prime}$ N, 42 ${ }^{\circ} 71.516^{\prime}$ E, alt. 200 m, 13 Nov. 2012, M.R. Sharaf leg. (CASENT0906493) (KSMA).

\section{Description}

MEASUREMENTS. (Holotype in brackets) EL 0.17-(0.20); FRS 0.20-0.21; HFL 0.61-(0.62); HFW 0.11(0.12); HL 0.63-(0.67); HW 0.50-(0.53); IOD 0.39-(0.42); OMD 0.14-(0.15); PPTL (0.14)-0.15; PPTH (0.15)-0.16; PPTW 0.21-(0.23); PTL (0.14)-0.15; PTH (0.20)-0.21; PTW 0.12-(0.13); SPST 0.21-(0.24); PW 0.35-(0.36); SL 0.49-(0.50); WL 0.74-(0.75); CI (79)-79; OI 34-(38); FI 122-(117); PI 34-(36); PSLI 33-(35); SI (75)-78 ( $\mathrm{n}=6)$.

HEAD. Longer than broad in frontal view (CI 79), lateral margins converge anteriorly and posteriorly; posterior margin weakly concave in middle; antenna 12-segmented; scapes large, clavate, when laid back from their insertions fail to reach posterior margin of head (SI 75-78); eyes prominent, situated about at midline on head sides (EL 0.17-0.20, IOD 0.39-0.42); median lobe of clypeus protruding forwards, with a weak submedian carinae; mandibles triangular, with masticatory margin armed with 4-5 

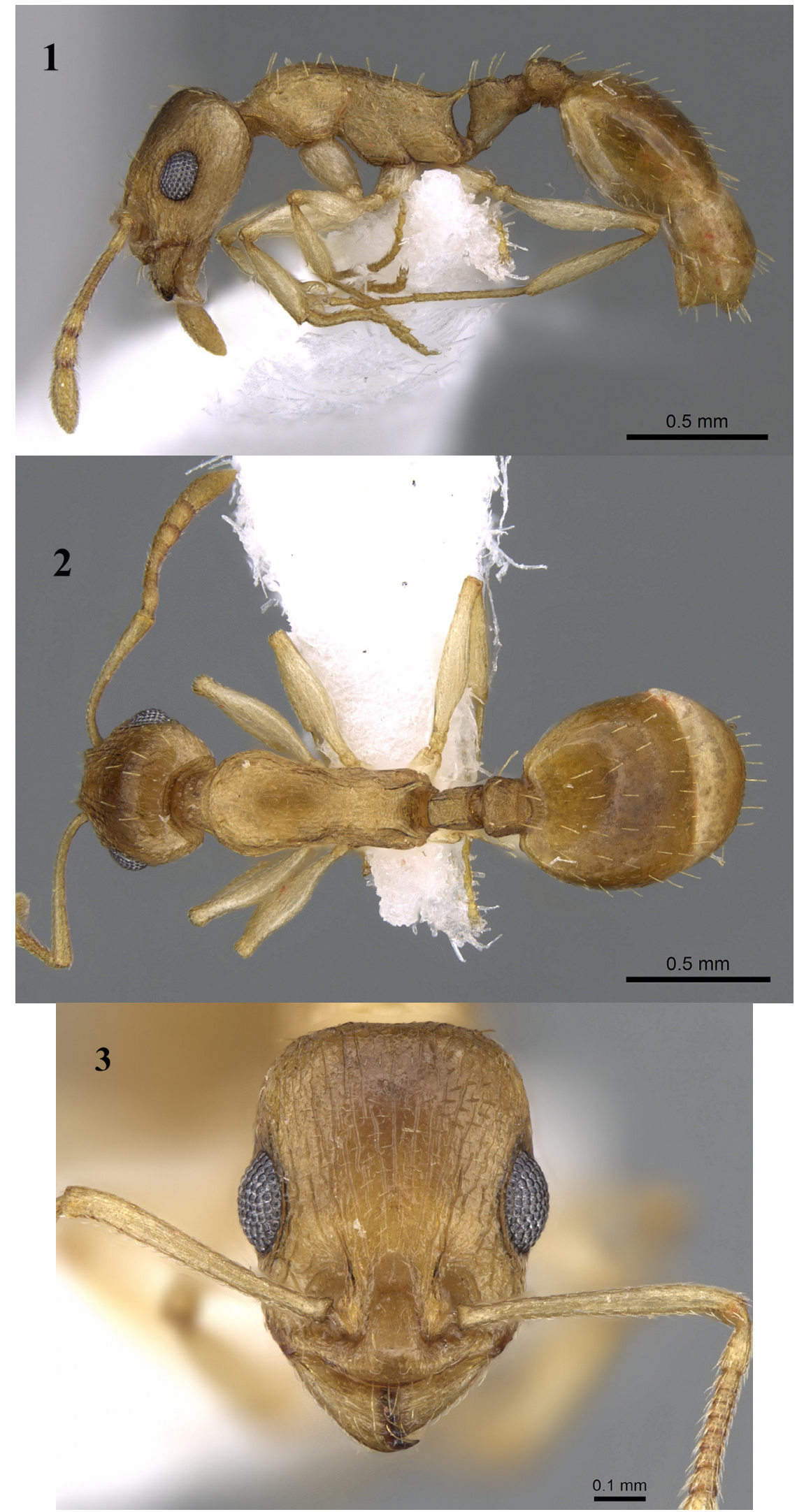

Figs 1-3. Temnothorax arabicus Sharaf \& Akbar sp. nov., holotype, worker (CASENT0746640) 1. Body in profile. 2. Body in dorsal view. 3. Head in frontal view. 
prominent teeth. Mesosoma slender (WL 0.74-0.75); in profile, mesosoma forming almost a continuous arch; metanotal groove weakly impressed; humeri in dorsal view rounded; propodeal spines long and sharp with acute tips (PSLI 33-35), slightly longer than distance between their bases; metafemur much longer than wide in dorsal view (HFL 0.61-0.62, HFW 0.11-0.12). Petiole node highest anteriorly, with a slightly concave anterior face and flat dorsum, sloping downwards to the posterior face; subpetiolar process reduced. Postpetiole node rounded in profile and trapezoidal in dorsal view. Gaster ovate, smooth and shiny; basal half of first tergite slightly roughened, becoming increasingly shiny and weakly sculptured.

HEAD AND BODY. Uniformly pale brownish yellow to light brown, head and gaster slightly darker. Head, median lobe of clypeus and supraclypeal area, smooth and shiny; longitudinal rugae distinct over cephalic surface in full-face view; mesosoma weakly reticulate-rugolose. Petiole and postpetiole nodes dull and finely reticulate, without much rugae. Vertex, frons and frontal lobes with few erect hairs; clypeus with a single erect hair on each side of median lobe in addition to usual long curled hairs along anterior margin. Erect hairs also present throughout mesosoma; petiole and postpetiole with several erect hairs which are longer than mesosomal pilosity; all gastral tergites with scattered short, erect or suberect hairs.

\section{Ecology}

The holotype and a single paratype specimen were collected in a pitfall trap set in the Asir Mountains. Other paratype specimens were collected by sifting soil from litter samples taken under a palm tree Hyphaene thebaica (L.) Mart. (Arecaceae) in the provinces of Jizan and Al Bahah in Saudi Arabia.

\section{Remarks}

The new species is a member of the T. laurae (Prebus, 2015) species group of the Afrotropical Region. Among the poorly known species from the region, $T$. arabicus sp. nov. seems to have affinities with T. mpala Prebus, 2015 from Kenya. The two species can be easily differentiated through a combination of characteristics. T. arabicus sp. nov. = head longer than broad (CI 79), lateral margins strongly converge anteriorly and posteriorly, smaller propodeal Spine Index (PSLI 33-35), clypeus smooth and shiny without any prominent median or longitudinal rugae, cephalic dorsum with feeble longitudinal rugae and pilosity prominent; whereas . mpala $=$ head subrectangular, longer than broad (CI 72-76), lateral sides parallel, slightly converging towards the mandibular insertions, higher propodeal Spine Index (PSLI 25-27), clypeus with strongly developed median ruga and much more prominent longitudinal rugae, cephalic dorsum reticulate, and pilosity sparse.

The two species differ considerably in morphometrics as well (in T. arabicus sp. nov., PTL 0.14-0.15; PTH 0.20-0.21; PTW 0.12-0.13 compared with PTL 0.20-0.23; PTH 0.19-0.22; PTW 0.16-0.17 in T. mpala) and postpetiole (in T. arabicus sp. nov., PPTH 0.15-0.16; PPTL 0.14-0.15; PPTW 0.21-0.23 compared with PPTH 0.17-0.18; PPTL 0.12-0.15; PPTW 0.22-0.24 in T. mpala).

Temnothorax liviae (Agosti \& Collingwood, 2011) comb. nov.

Figs 4-9

Leptothorax liviae Agosti \& Collingwood in Collingwood et al. 2011: 430, pl. 44-46, figs 36-37 (combined in Temnothorax by Bolton (2017), not formally published, see http://antcat.org).

\section{Material examined}

Holotype

UNITED ARAB EMIRATES: Baynunah sand desert, 234ㅇ' N, 5300' E, 2 Mar. 1995, CASENT0102700. 

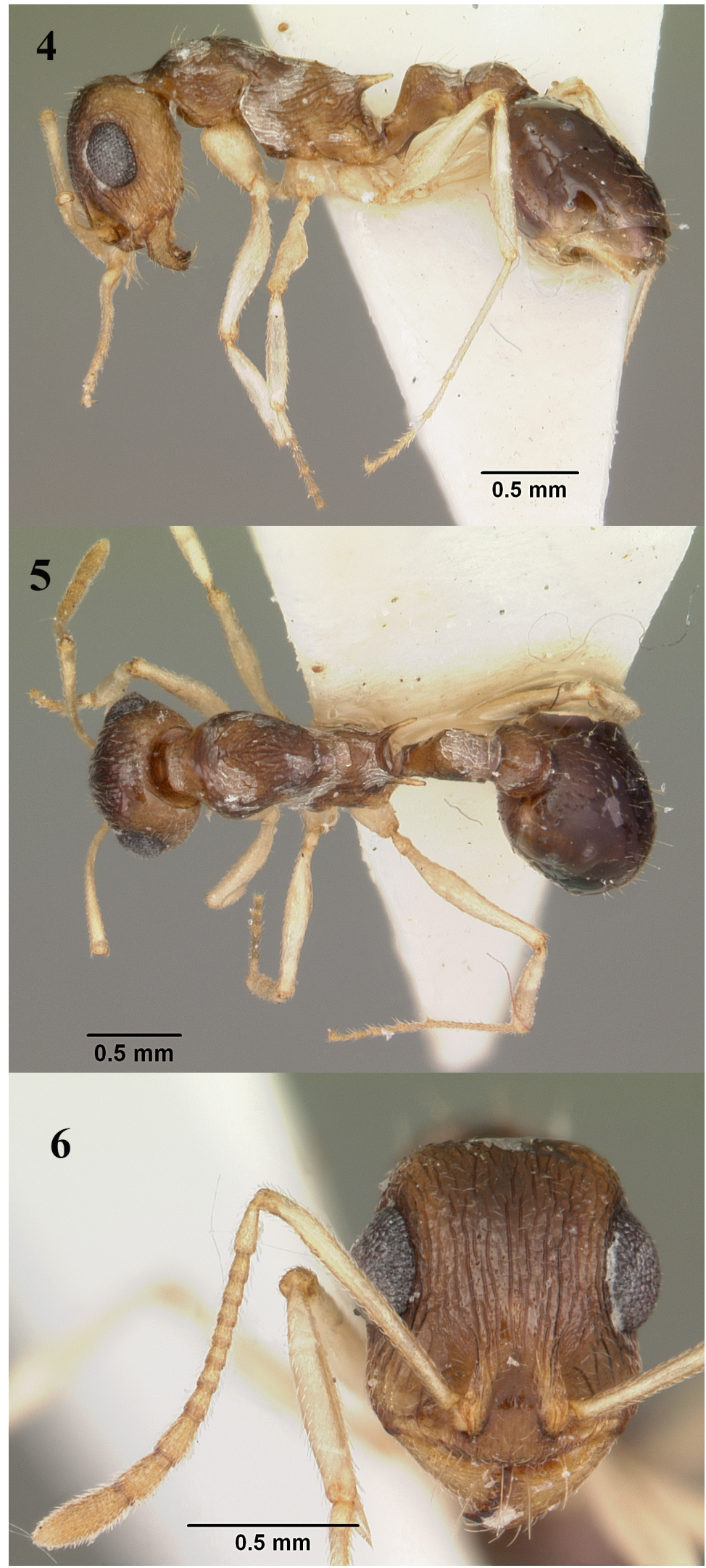

Figs 4-6. Temnothorax liviae (Agosti \& Collingwood, 2011) comb. nov., holotype, worker (CASENT0102700). 4. Body in profile. 5. Body in dorsal view. 6. Head in frontal view. 


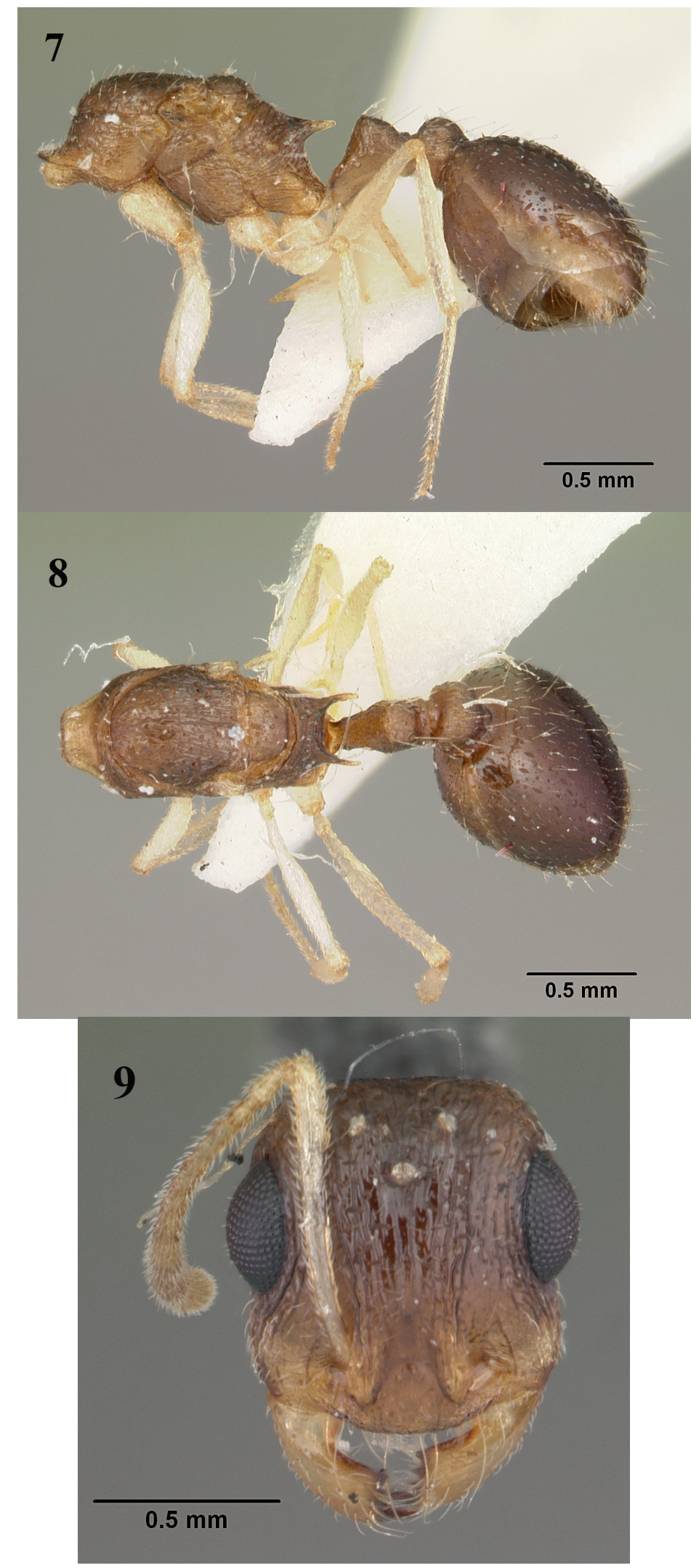

Figs 7-9. Temnothorax liviae (Agosti \& Collingwood, 2011) comb. nov., queen (CASENT0102699). 7. Body in profile. 8. Body in dorsal view. 9. Head in frontal view. 


\section{Paratype}

UNITED ARAB EMIRATES: 1 dealate q, Baynunah sand desert, $23.8333^{\circ} \mathrm{N}, 52.8333^{\circ}$ E, 3 Dec. 1994 , B. Tigar \& C.A. Collingwood leg. (CASENT0102699) (NHMB).

\section{Description}

\section{Holotype worker}

MEASUREMENTS. EL 0.33; FRS 0.26; HFL 0.83; HFW 0.13; HL 0.94; HW 0.72; IOD 0.65; OMD 0.18; PPTL 0.26; PPTH 0.25; PPTW 0.42; PTL 0.46; PTH 0.37; PTW 0.26; SPST 0.32; PW 0.53; SL 0.86; WL 1.16; CI 77; OI 46; FI 115; PI 49; PSLI 34; SI 119 (n=1).

HEAD. Distinctly longer than broad (CI 77), with straight posterior and lateral margins; eyes massive (EL $0.45 \times \mathrm{HW}$ ), with 20 ommatidia in longest row; frontal carinae short extending back only as far as the anterior level of eyes; scapes relatively long (SI 119), when laid back from their insertions clearly surpassing posterior margin of head. Mesosoma slender (WL 1.16); metanotal groove shallow but distinct; propodeal dorsum nearly straight or feebly convex; propodeal spines long, sharp and acute (PSLI 34); anterior pronotal corners distinctly rounded in dorsal view. In profile, petiole distinctly longer than broad (PI 49), with convex dorsum. Postpetiole distinctly broader than long.

BoDy. Pale brown, gaster dark brown, antennae, mandibles and legs yellow. Cephalic dorsum strongly, longitudinally and irregularly striate; mandibles feebly longitudinally striate; mesosoma irregularly longitudinally striate; petiole and postpetiole feebly and superficially sculptured; gaster smooth and shining. Cephalic dorsum with many sparse short hairs; underside of head with a few short curved hairs; mesosomal pilosity restricted to three pairs on pronotal angles, two on mesonotum and two short pairs on propodeal dorsum; petiole with two pairs of long back directed hairs; postpetiole with three pairs of long hairs; gaster with many scattered shorter hairs.

\section{Queen}

MEASUREMENTS. EL 0.35; FRS 0.27; HFL 0.85; HFW 0.14; HL 1.01; HW 0.75; IOD 0.67; OMD 0.21; IOcD 0.19; PPTL 0.29; PPTH 0.27; PPTW 0.45; PTL 0.50; PTH 0.40; PTW 0.28; SPST 0.32; PW 0.57; SL 0.87; WL 1.24; CI 74; OI 46; FI 113; PI 49; PSLI 31; SI 80 (n=1).

HEAD AND BODy. Similar to the workers from the same colony but larger, with thicker body, especially mesosoma and gaster. Ocelli present, prominent. Pilosity is much more prominent compared to the workers.

\section{Ecology}

Specimens were collected in a pitfall trap from Baynunah, a sandy desert in United Arab Emirates (UAE). The species is known only from its type locality.

\section{Remarks}

Despite the absence of formally published data, Leptothorax liviae has long been treated as a member of the genus Temnothorax (Bolton 2017). This generic placement of the species is obvious from the presence of a median clypeal carina, the absence of a transverse crest on the stipes, and the 12-segmented antennae, typical of Temnothorax. Based on Bolton's unpublished opinion and examination of the material during the present study, Leptothorax liviae is hereby validated as Temnothorax liviae (Agosti \& Collingwood, 2011) comb.nov. 
Temnothorax megalops (Hamann \& Klemm, 1967)

Figs 10-15

Leptothorax (Icothorax) megalops Hamann \& Klemm 1967: 417, fig. 1 (w.q.).

Temnothorax megalops - Bolton 2003: 271; 1982: 331.

Material examined

Holotype

SUDAN: Wadi Halfa, wet ditch, 28 Jan. 1962, H. Hamann \& W. Klemm leg. (CASENT0712601).

Paratype

SUDAN: 1 dealate q, same data as holotype (CASENT0712600) (NHMW).

\section{Other material examined}

YEMEN: 1 q, Al Kawd, $13.08861^{\circ} \mathrm{N}, 45.36472^{\circ}$ E, 7 Sep. 2001, Van Harten leg., code 6770 (CASENT0906380) (WMLC); 1 q, Jun. 1999, Van Harten leg., code 8877 (CASENT0922183) (WMLC); 1 q, Al Kawd, $13.08861^{\circ}$ N, 45.36472 ${ }^{\circ}$ E, Sep. 1999, Van Harten leg., 4170 (CASENT0922180) (WMLC).

\section{Remarks}

The species was recently treated by Prebus (2015), who provided a complete diagnosis.

\section{Ecology}

This species was described from Sudan and was recently recorded from the UAE (Sharjah Desert Park, $25^{\circ} 22.021 \mathrm{~N}, 055^{\circ} 40.264 \mathrm{E}$, Wadi Wurayah, $25^{\circ} 24^{\prime} \mathrm{N}, 56^{\circ} 15^{\prime} \mathrm{E}$ ) (Collingwood et al. 2011).

\section{Note}

The specimen with code CASENT0906379 labelled on AntWeb as a worker specimen of T. megalops (collected from Yemen, Abyan, Al Kawd, 7 Sep. 2001, 13.08861 ${ }^{\circ}$ N, $45.36472^{\circ}$ E, Van Harten leg., WMLC), actually represents a species of Nesomyrmex that has been misidentified and placed in Temnothorax.

\section{Key to species of Temnothorax of the Arabian Peninsula}

1 Uniformly yellow; $\mathrm{HW}<0.55$; $\mathrm{PI}<40$; IOD $<0.45$

- Uniformly brown or blackish brown species; HW>0.60; PI $>45$; IOD $>0.55$ (United Arab Emirates) T. liviae (Agosti \& Collingwood, 2011) comb. nov.

2 Cephalic dorsum nearly smooth and shiny with feeble longitudinal striae in full-face view; frontal carinae feeble, running back to anterior level of eyes; propodeal spines short and blunt; petiole with a single pair of distinctly erect hairs; mesosomal dorsum feebly, longitudinally, rugose on pronotum and mesonotum, reticulate on propodeum. (Sudan and United Arab Emirates)

..T. megalops (Hamann \& Klemm, 1967)

Cephalic dorsum strongly, longitudinally, irregularly striate in full-face view; frontal carinae more developed, running back to midlevel of eyes; propodeal spines long and sharp; petiole with two pairs of normal hairs; mesosoma weakly reticulate-rugose. (KSA)

..T. arabicus Sharaf \& Akbar sp. nov. 


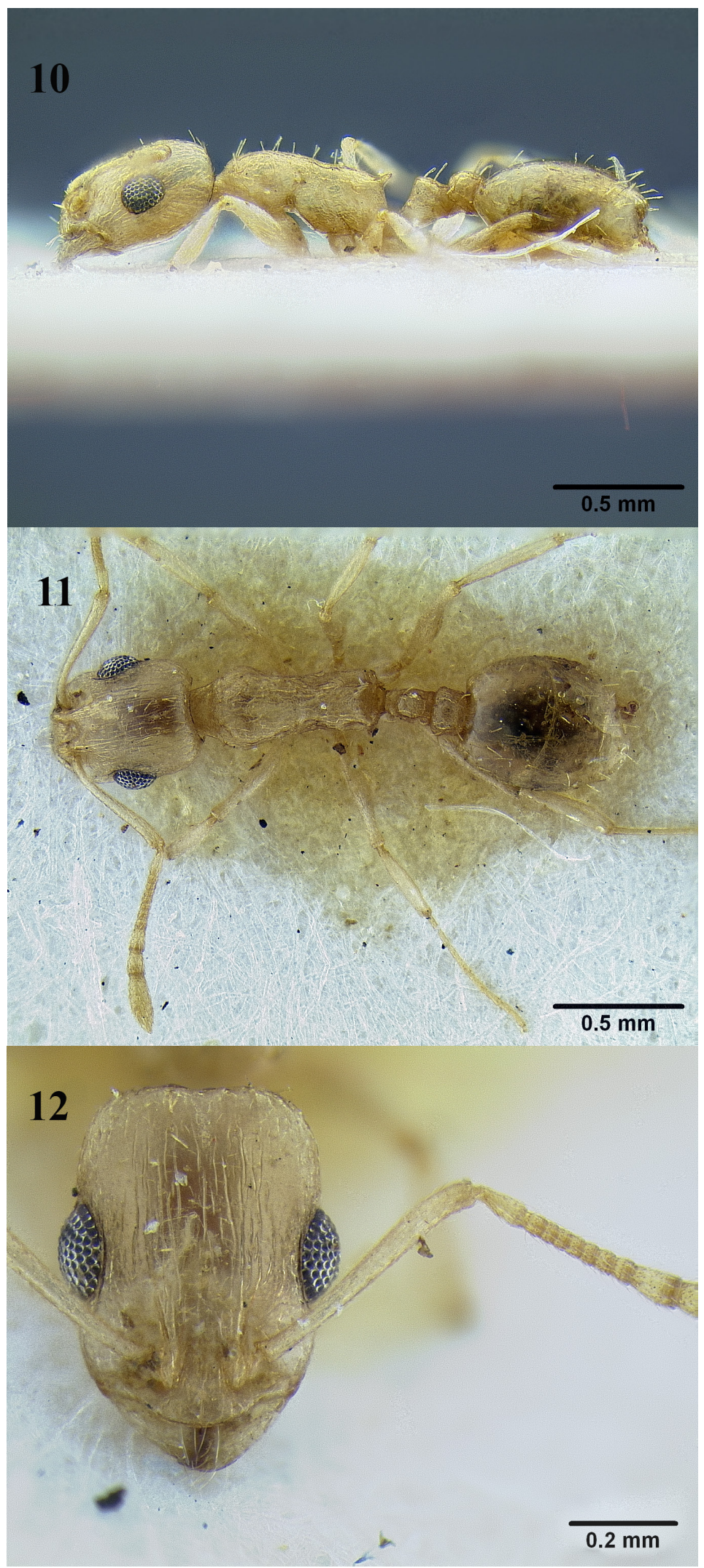

Figs 10-12. Temnothorax megalops (Hamann \& Klemm, 1967), holotype, worker (CASENT0712601). 10. Body in profile.11. Body in dorsal view. 12. Head in frontal view. 


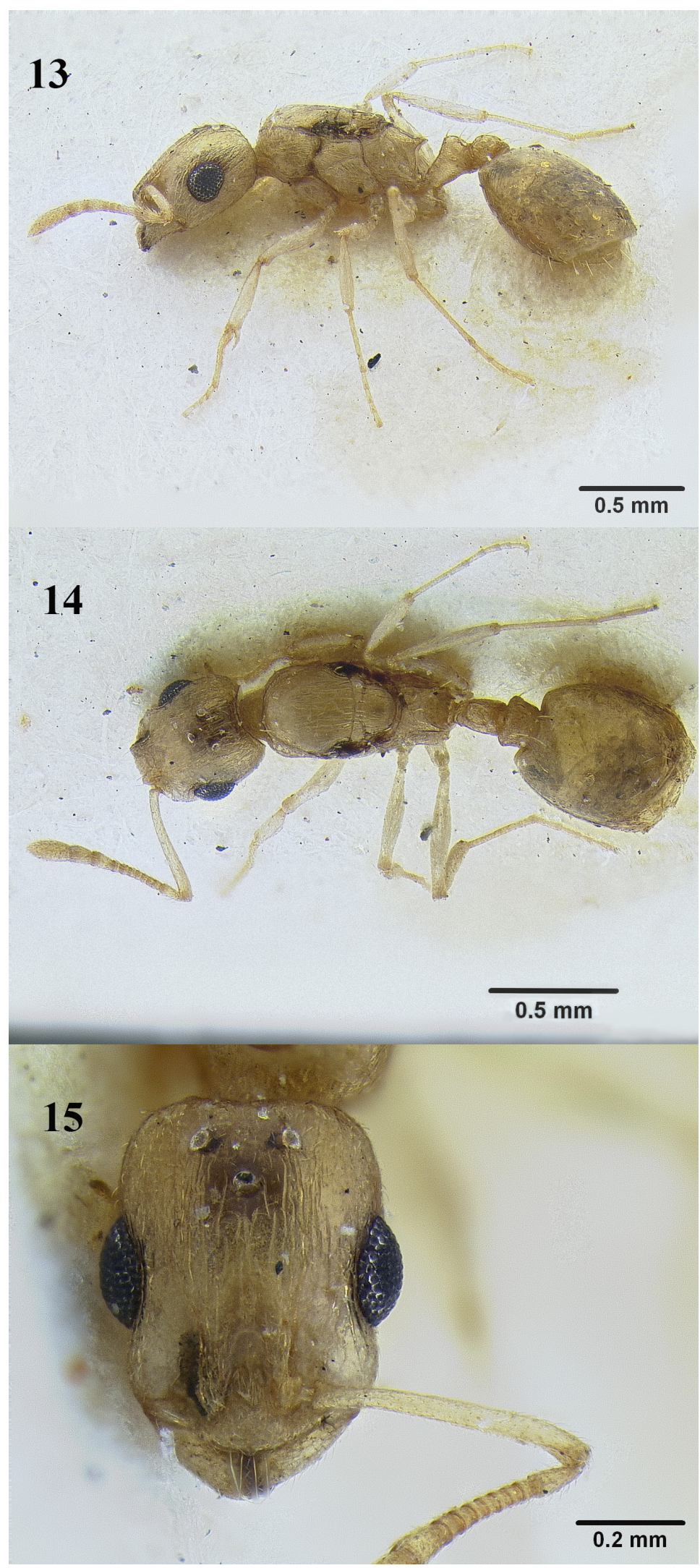

Figs 13-15. Temnothorax megalops (Hamann \& Klemm, 1967), queen (CASENT0712600). 13. Body in profile. 14. Body in dorsal view. 15. Head in frontal view. 


\section{Species excluded from synonomy of Temnothorax}

Tetramorium saudiae (Collingwood \& Agosti, 1996) comb. nov.

Figs $16-18$

Leptothorax saudiae Collingwood \& Agosti, 1996: 325, fig. 9 (w).

Temnothorax saudiae - Bolton 2003: 271.

\section{Material examined}

Holotype worker

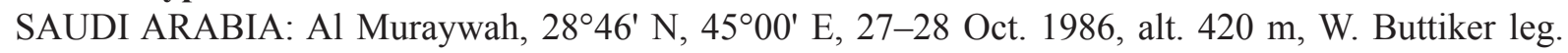
(CASENT0922184) (WMLC).

\section{Remarks}

Collingwood \& Agosti (1996) described Leptothorax saudiae based upon a single specimen deposited in WMLC. The specimen in WMLC with a red label [Saudi Arabien, Al Muraywah, $2846 \mathrm{~N}, 4500 \mathrm{E}$, $27-28$ Oct. $86,420 \mathrm{~m}$, W. Buttiker] is not specified as the holotype, yet the label information matches the original description exactly. This specimen, therefore, definitely represents the Leptothorax saudiae holotype. However, contrary to Bolton's transferral of the species to Temnothorax (Bolton 2003), this specimen clearly belongs to the genus Tetramorium based on the following observations: it possesses lateral portions of clypeus that are raised into sharp ridges or shield walls in front of the antennal insertions and the propodeal spiracles are low on the sides and distinctly behind the midlength of the sclerite. This taxon is herein formally transferred to the genus Tetramorium.

\section{Discussion}

The genus Temnothorax is represented by only three valid species from the Arabian Peninsula. These are T. arabicus sp. nov., T. liviae comb. nov., and T. megalops. These three species have been infrequently encountered in collections. Temnothorax liviae comb. nov. may be considered rarest among the known regional species, having been reported so far from its type locality only. The Temnothorax fauna of the Arabian Peninsula has its closest affinity with the T. laurae species group from Iberia, North and East Africa. The group is characterized by an elongate head capsule, large eyes with distinct micropilosity between the facets (there is, however, no sign of such micropilosity on any of the AntWeb photographs of the species), trapezoidal petiole, coarsely striate sculpture and impressed metanotal groove (Cagniant \& Espadaler 1997; Tinaut 1995; Prebus 2015).

\section{Acknowledgements}

The authors would like to extend their sincere appreciation to the Deanship of Scientific Research at the King Saud University for funding this Research group NO (RGP -1436-029). The authors are grateful to Boris Kondratieff, Sándor Csősz, Matthew Prebus and an anonymous reviewer for suggestions and comments regarding the manuscript. Special thanks are also due to Brian Fisher and the AntWeb team (www.antweb.org) for their much appreciated assistance in photographing the species. Mostafa Sharaf is grateful to Tony Hunter (Entomology Curator, WML) and Stephen Judd (Director, WML) for appreciated support during a visit to the U.K., and to Tony van Harten for providing material from Arabia. 


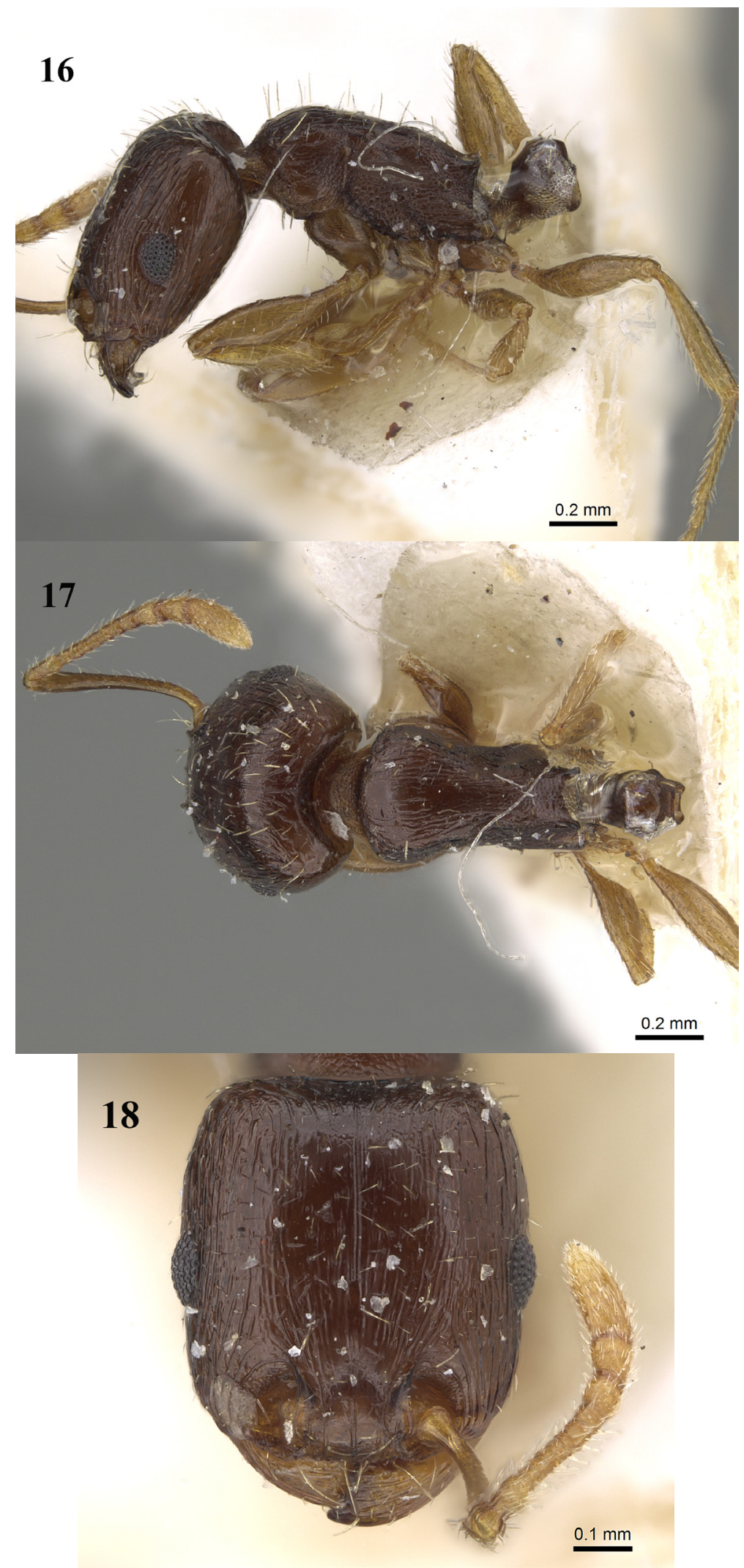

Figs 16-18. Tetramorium saudiae (Collingwood \& Agosti, 1996), holotype, worker (CASENT0922184). 16. Body in profile.17. Body in dorsal view. 18. Head in frontal view. 


\section{References}

Aleksiev A., Franks A.B.S. \& Franks N.R. 2007. Nest 'moulting' in the ant Temnothorax albipennis. Animal Behaviour 74: 567-575. http://dx.doi.org/10.1016/j.anbehav.2006.12.023

Baroni Urbani C. 1978. Materiali per una revisione dei Leptothorax neotropicali appartenenti al sottogenere Macromischa Roger, comb. nov. (Hymenoptera: Formicidae). Entomologica Basiliensis 3: 395-618.

Basari N., Laird-Hopkins B.C., Sendova-Franks A.B. \& Franks N.R. 2014. Trail laying during tandemrunning recruitment in the ant Temnothorax albipennis. Naturwissenschaften 101 (7): 549-556. http:// dx.doi.org/10.1007/s00114-014-1191-1

Bharti H., Gul I. \& Schulz A. 2012. Three new species of genus Temnothorax from Indian Himalayas with a revised key to the Indian species. Acta Zoologica Academiae Scientiarum Hungaricae 58: 325-336.

Bharti H., Gul I. \& Sasi S. 2016. Taxonomy of Temnothorax simlensis stat. nov. (Hymenoptera: Formicidae) with first description of sexual castes along with a mention of its plesiobiotic association with Himalayan species of genus Myrmica. Sociobiology 63(2): 748-754. http://dx.doi.org/10.13102/ sociobiology.v63i2.869

Bolton B. 1982. Afrotropical species of the myrmicine ant genera Cardiocondyla, Leptothorax, Melissotarsus, Messor and Cataulacus (Formicidae). Bulletin of the British Museum (Natural History). Entomology 45: 307-370.

Bolton B. 2003. Synopsis and classification of Formicidae. Memoirs of the American Entomological Institute 71: 1-370.

Bolton B. 2017. An online catalog of the ants of the world. Available from http://antcat.org [accessed 29 Jan. 2017]

Buschinger A. 1968. Mono- und Polygynie bei Arten der Gattung Leptothorax Mayr (Hymenoptera Formicidae). Insectes Sociaux 15: 217-226.

Buschinger A. 1974. Experimente und Beobachtungen zur Gründung und Entwicklung neuer Sozietäten der sklavenhaltenden Ameise Harpagoxenus sublaevis (Nyl.). Insectes Sociaux 21: 381-406.

Buschinger A. 1981. Biological and Systematic Relationships of Social Parasitic Leptothoracini from Europe and North America. In: Howse P.E. \& Clement J-L. (eds) Biosystematics of social insects. Systematics Association Special Volume. Vol. 19: 211-222. Academic Press, London.

Buschinger A. 1986. Evolution of social parasitism in ants. TREE 1: 155-160.

BuschingerA. 2009. Social parasitism among ants: a review (Hymenoptera: Formicidae). Myrmecological News 12: 219-235.

Cagniant H. \& Espadaler X. 1997. Les Leptothorax, Epimyrmaet Chalepoxenusdu Maroc (Hymenoptera: Formicidae). Clé et catalogue des espèces. Annales-Société Entomologique de France 33: 259-284.

Collingwood C.A. \& Agosti D. 1996. Formicidae (Insecta: Hymenoptera) of Saudi Arabia (part 2). In: Krupp F. \& Mahnert V. (eds) Fauna of Saudi Arabia 15: 300-385. Karger Libri, Basel.

Collingwood C.A., Agosti D., Sharaf M.R. \& van Harten A. 2011. Order Hymenoptera, Family Formicidae. In: van Harten A. (ed.) Arthropod Fauna of the UAE 4: 405-474. Dar Al Ummah, Abu Dhabi.

Csősz S., Heinze J. \& Mikó I. 2015. Taxonomic Synopsis of the Ponto-Mediterranean ants of Temnothorax nylanderi species-group. PLoS ONE 10 (11): e0140000. http://dx.doi.org/10.1371/journal. pone. 0140000 
CzechowskiW., RadchenkoA., Czechowska W. \& Vepsäläinen K. 2012. The ants of Poland, with reference to the myrmecofauna of Europe. Fauna Poloniae (N.S.) 4. Natura optima dux Foundation, Warsaw.

Dornhaus A. \& Franks N.R. 2006. Colony size affects collective decision-making in the ant Temnothorax albipennis. Insectes Sociaux 53 (4): 420-427.

Fisher B.L. \& Cover S.P. 2007. Ants of North America: a guide to genera. University of California Press, Berkeley.

Fokuhl G., Heinze J. \& Poschlod P. 2012. Myrmechory by small ants - Beneficial effects through elaiosome nutrition and seed dispersal. Acta Oecologica 38: 71-76.

Franks N.R. \& Richardson T. 2006. Teaching in tandem-running ants. Nature 439 (7073): 153-153. http://dx.doi.org/10.1038/439153a

Galkowski P.C. \& Lebas C. 2016. Temnothorax conatensis nov. sp., décrite des Pyrénées-Orientales (France) (Hymenoptera, Formicidae). Revue de l'Association Roussillonnaise d'Entomologie. Tome XXV (2): $80-87$.

Hamann H.H.F. \& Klemm W. 1967. Ergebnisse der zoologischen Nubien-Expedition 1962. Teil XXXIV. Hymenoptera - Formicidae. Annalen des Naturhistorischen Museums in Wien 70: 411-421.

Heinze J. 2004. Reproductive conflict in insect societies. Advances in the Study of Behavior 34: 1-57. http://dx.doi.org/10.1016/S0065-3454(04)34001-5

Hita G.F., Mbanyana N., Audisio T.L. \& Alpert G.D. 2017. Taxonomy of the ant genus Nesomyrmex Wheeler (Formicidae, Myrmicinae) in the Afrotropical region, with a review of current species groups and description of a new species of the $N$. angulatus group from Mozambique. European Journal of Taxonomy 258: 1-31. http://dx.doi.org/10.5852/ejt.2017.258

Hölldobler B. \& Wilson E.O. 1990. The Ants. Springer Verlag, Heidelberg, Berlin.

Mackay W.P. 2000. A review of the New World ants of the subgenus Myrafant, (Genus Leptothorax) (Hymenoptera: Formicidae). Sociobiology 36: 265-444.

Mayr G. 1861. Die Europäischen Formiciden. (Ameisen). Nach der analytischen Methode bearbeitet. Gerold, Vienna.

Plateaux L. \& Cagniant C. 2012. Quelques synonymies dans le genre Temnothorax Mayr, 1855 (Hymenoptera, Formicidae). Bulletin de la Société entomologique de France 117: 427-440.

Pratt S.C., Sumpter D.J.T., Mallon E.B. \& Franks N.R. 2005. An agent-based model of collective nest choice by the ant Temnothorax albipennis. Animal Behaviour 70: 1023-1036. http://dx.doi.org/10.1016/j. anbehav.2005.01.022

Prebus M. 2015. Palearctic elements in the old world tropics: a taxonomic revision of the ant genus Temnothorax Mayr (Hymenoptera, Formicidae) for the Afrotropical biogeographical region. ZooKeys 483: 23-57. http://dx.doi.org/10.3897/zookeys.483.9111

Radchenko A.G. 2005. Monographic revision of the ants of North Korea. Annales Zoologici (Warszawa) 55: 127-221.

Radchenko A.G. 2004. A review of the ant genera Leptothorax Mayr and Temnothorax Mayr of the eastern Palaearctic. Acta Zoologica Academiae Scientiarum Hungaricae 50: 109-137.

Reyes-López J.L. \& Carpintero-Ortega S. 2013. Descripción de Temnothorax bejaraniensis nov. sp. (Hymenoptera, Formicidae), una nueva especie para la península Ibérica. Boletín Sociedad Entomológica Aragonesa 52: 23-28.

Salata S. \& Borowiec L. 2015. Redescription of Temnothorax antigoni (Forel, 1911) and description of its new social parasite Temnothorax curtisetosus sp. n. from Turkey (Hymenoptera, Formicidae). ZooKeys 523: 129-148. http://dx.doi.org/10.3897/zookeys.523.6103 
Schulz A., Heinze J. \& Pusch K. 2007. Description of two new Temnothorax species from Italy. Zootaxa 1471: $1-14$.

Seifert B. 2006. Temnothorax saxonicus (Seifert, 1995) stat.n., comb.n. - a parapatric, closely-related species of T. sordidulus (Muller, 1923) comb.n. and description of two new closely-related species, T. schoedli sp.n. and T. artvinense sp.n., from Turkey (Hymenoptera: Formicidae). Myrmecologische Nachrichten 8: 1-12.

Seifert B. 2007. Die Ameisen Mittel- und Nordeuropas. Lutra Verlags- und Vertriebsgesellschaft, Klitten.

Seifert B., Buschinger A., Aldawood A., Antonova V., Bharti H., Borowiec L., Dekoninck W., Dubovikoff D., Espadaler X., Flegr J., Georgiadis C., Heinze J., Neumeyer R., Ødegaard F., Oettler J., Radchenko A., Schultz R., Sharaf M., Trager J., Vesnić A., Wiezik M. \& Zettel H. 2016. Banning paraphylies and executing Linnaean taxonomy is discordant and reduces the evolutionary and semantic information content of biological nomenclature. Insectes Sociaux 63 (2): 1-6. http://dx.doi.org/10.1007/s00040-016$\underline{0467-1}$

Seifert B. \& Csősz S. 2015. Temnothorax crasecundus sp. n.-a cryptic Eurocaucasian ant species (Hymenoptera, Formicidae) discovered by Nest Centroid Clustering. ZooKeys 479: 37-64. http://dx.doi. org/10.3897/zookeys.479.8510

Sharaf M.R., Fisher B.L., Collingwood C.A. \& Aldawood A.S. 2017. Ant fauna (Hymenoptera: Formicidae) of the Socotra Archipelago (Yemen): zoogeography, distribution and description of a new species. Journal of Natural History. http://dx.doi.org/10.1080/00222933.2016.1271157

Snelling R.R., Borowiec M.L. \& Prebus M.M. 2014. Studies on California ants: a review of the genus Temnothorax. ZooKeys 372: 27-89. http://dx.doi.org/10.3897/zookeys.372.6039

Terayama M. 2009. A synopsis of the family Formicidae of Taiwan. Research Bulletin of Kanto Gakuen University 17: 81-266.

Tinaut A. 1995. Nueva especie de Leptothorax(Mayr, 1855) del groupo lauraeEmery, 1884 Leptothorax crepuscularis n. sp. (Hymenoptera, Formicidae). Zoologica Baetica 5: 89-98.

Ward P.S., Brady S.G., Fisher B.L., \& Schultz T.R. 2015. The evolution of myrmicine ants: phylogeny and biogeography of a hyperdiverse ant clade (Hymenoptera: Formicidae). Systematic Entomology 40: 61-81. http://dx.doi.org/10.1111/syen.12090

Zhou S., Huang J., Yu D. \& Liu Z. 2010. Eight new species and three newly recorded species of the ant genus Temnothorax Mayr from the Chinese mainland, with a key. Sociobiology 56: 7-26.

\author{
Manuscript received: 5 April 2016 \\ Manuscript accepted: 13 July 2016 \\ Published on: 16 February 2017 \\ Topic editor: Gavin Broad \\ Desk editor: Chloe Chester
}

Printed versions of all papers are also deposited in the libraries of the institutes that are members of the EJT consortium: Muséum national d'Histoire naturelle, Paris, France; Botanic Garden Meise, Belgium; Royal Museum for Central Africa, Tervuren, Belgium; Natural History Museum, London, United Kingdom; Royal Belgian Institute of Natural Sciences, Brussels, Belgium; Natural History Museum of Denmark, Copenhagen, Denmark; Naturalis Biodiversity Center, Leiden, the Netherlands. 